\title{
Human papillomavirus: vaccination, related cancer awareness, and risk of transmission among female medical students
}

\author{
Pavel V. Chernyshov ${ }^{\bowtie}$, Iryna Humenna²
}

\begin{abstract}
Introduction: The human papillomavirus (HPV) vaccination has not yet been integrated into the national immunization program in Ukraine, and the vaccination rate is low. The objectives of our study were to investigate HPV vaccination prevalence and knowledge, risk of HPV transmission, and HPV-related cervical cancer awareness in female medical students.

Methods: Female medical students at Bohomolets National Medical University in their 2nd through 6th years of the program completed an anonymous survey on HPV infection and vaccination.

Results: A total of 640 surveys were analyzed. Knowledge about HPV vaccination was reported by $57.3 \%$ of respondents. The reported vaccination rate was $1.7 \%$. HPV-related cervical cancer awareness was reported by $81.1 \%$. More than $30 \%$ of the respondents were not yet sexually active.

Conclusions: Female medical students showed low knowledge of HPV vaccination and an extremely low HPV vaccination rate, but a higher level of HPV-related cervical cancer awareness. A substantial number of students were not yet sexually active or had never had sex without a condom. HPV vaccination is thus still important for our respondents. There is an emerging need in educational programs for students starting from their first semester of the program and for a broader informational campaign focused on schoolchildren and their parents.
\end{abstract}

Keywords: HPV, medical students, knowledge, vaccination, cervical cancer awareness, Ukraine

Received: 30 April 2019 | Returned for modification: 10 May 2019| Accepted: 17 May 2019

\section{Introduction}

According to Institut Catala d'Oncologia Information Centre on human papillomavirus (HPV) and Cancer 2017 Information Report, Ukraine has a population of 20.5 million women aged 15 and older that are at risk of developing cervical cancer. Current estimates indicate that every year 5,733 women are diagnosed with cervical cancer and 2,475 die from the disease. Cervical cancer is the fourth most frequent cancer among women in Ukraine and the second most frequent cancer among women between ages 15 and 44. Data are not yet available on the HPV burden in the general population of Ukraine. However, in eastern Europe, the region Ukraine belongs to, about $9.7 \%$ of women in the general population are estimated to harbor cervical HPV16/HPV18 infection at a given time, and $84.7 \%$ of invasive cervical cancers are attributed to HPV16 or HPV18 (1). HPV vaccination is not yet integrated into the national immunization program, however, there are some limited regional programs for vaccination of 9- to 15-year-old girls with a limited number of 2-valent vaccines for two vaccination rounds (2-4). These programs can cover only a minority of the target population and the HPV vaccination rate in Ukraine is expected to be low, as in other European countries without HPV vaccination programs funded from the national budget (5). Available HPV vaccination programs are focused on female undergraduate students. Young adults also should have the opportunity for vaccination at their own expense, but they should be aware of HPV-related risks, the possibility of being vaccinated, and its efficacy. To study the real situation regarding HPV knowledge and vaccination in young females, a pilot survey was performed among 4 th-year medical students at the second medical faculty of Bohomolets National
Medical University (6). Despite a high level of reported HPV-related cancer awareness, less than $45 \%$ of respondents knew about HPV vaccination and less than $5 \%$ were vaccinated against HPV. To make the educational campaign more effective, we decided to provide more detailed analysis of the risk factors and knowledge of students in various years of the program.

\section{Methods}

Ethical permission for this study was granted by the Ethics Committee of Bohomolets National Medical University (protocol no. 108, approval date: February 1st, 2018).

Female medical students at Bohomolets National Medical University in their 2nd through 6th years of the program completed an anonymous survey on HPV infection and vaccination. All participants provided informed consent for participation in the study. The questions on HPV-related cancer awareness, history of HPV testing, results of HPV tests, knowledge of HPV vaccination, HPV vaccination history, and start of sexual activity were previously used in a pilot study (6). Based on the analysis of the pilot study results, additional questions on the total number of sexual partners, number of sexual partners with unprotected vaginal intercourse, and age at first sexual intercourse were added to the survey. Inclusion criteria were: female sex and student at Bohomolets National Medical University in the 2nd through 6th years of the program. Informed consent was obtained after the nature and possible consequences of the study had been fully explained. Fisher's exact test (two-sided) was used to examine the significance of the association between the two kinds of classification. The results were considered significant if $p<0.05$. 


\section{Results}

Seven hundred fifty-two surveys were returned. Unrelated data, unreal data, and male sex were reasons for exclusion. Six hundred forty surveys were accepted and included for further analysis: 208 from students in their 2nd year of the program, 135 in their 3rd year, 103 in their 4th year, 78 in their 5th year, and 116 in their 6 th year.

Age was reported by 640 students. The mean age of students was $20.53 \pm 2.30$ years. Three students reported unreal data and therefore their answers were excluded from the analysis. The mean age of students was $18.95 \pm 1.33,20.33 \pm 2.90,20.74 \pm 1.10$, $21.81 \pm 0.91$, and $22.53 \pm 2.23$ for the 2 nd, 3rd, 4th, 5th, and 6th years of the program, respectively.

The majority of students (81.1\%) knew that HPV-infected females have an increased risk of developing cervical cancer. Reported HPV-related cervical cancer awareness in different years of the program is presented in Fig. 1. Third-year students reported significantly higher HPV-related cancer awareness than 2nd-year students $(p<0.001)$ but lower than 4 th-year students $(p<0.001)$. More than half of the respondents (57.3\%) knew about vaccination against HPV. Knowledge of HPV vaccination among students in different years of the program is presented in Fig. 2. A higher number of 3rd-year students knew about HPV vaccination in comparison to 2nd-year students $(p<0.001)$, but significantly fewer than among 4 th-year students $(p<0.001)$. The total number of vaccinated students was $11(1.7 \%)$, and $7(1.1 \%)$ of them were vaccinated before they became sexually active. Students' HPV vaccination rates in different years of the program are presented in Figure 3. All vaccinated students in their 2nd, 3rd, and 6th years of the program and half of the vaccinated 4 th-year students were vaccinated before they became sexually active. Both vaccinated students in the 5 th year of the program were vaccinated after they became sexually active. A total of $69.7 \%$ of students were sexually active. The proportion of sexually active students increased almost linearly with each year of the program.

Age of sexual debut was reported by 443 students. The mean age of sexual debut was $17.76 \pm 1.97$. Detailed information on the age of sexual debut is presented in Table 1 . The total number of sexual partners was also reported by 443 respondents. The mean total number of sexual partners was $4.02 \pm 15.95$. Detailed information on the reported number of sexual partners is presented in Table 2. The number of sexual partners with at least one unprotected act of vaginal intercourse was reported by 445 students. The mean number of sexual partners with at least one unprotected act of vaginal intercourse was $2.35 \pm 6.79$. Detailed information on the number of sexual partners with at least one unprotected act of vaginal intercourse is presented in Table 3.

\section{Discussion}

The vaccination rate in our students was very low: from $0.9 \%$ in 6th-year students to $3.9 \%$ in 4 th-year students. HPV vaccination is not yet widely available, and this may be the key to curtailing the spread of HPV infections in resource-poor countries (7). Several European countries, including Ukraine, have also not integrated HPV vaccination into the national immunization program. The key reason for this is the high vaccine cost (8). In contrast, a marked decline in HPV infection has occurred in countries where HPV vaccination programs started in 2008 and $2009(9,10)$. In the absence of a national HPV vaccination program, it is possible to

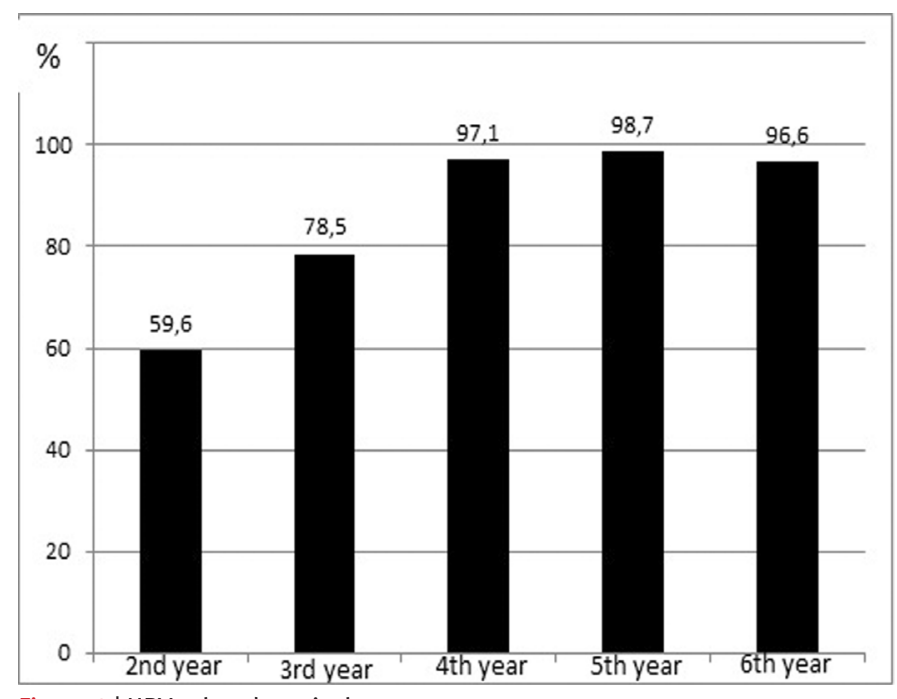

Figure 1 | HPV-related cervical cancer awareness.

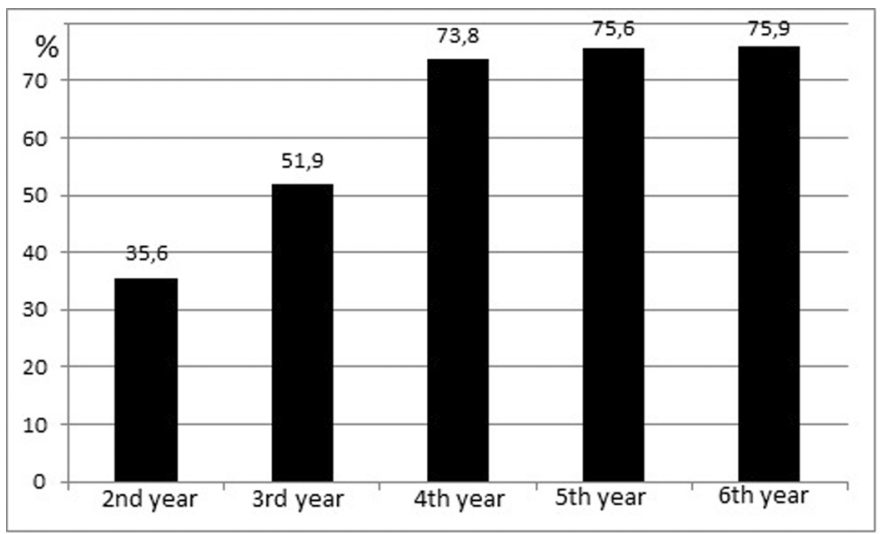

Figure 2 | Knowledge of HPV vaccination.

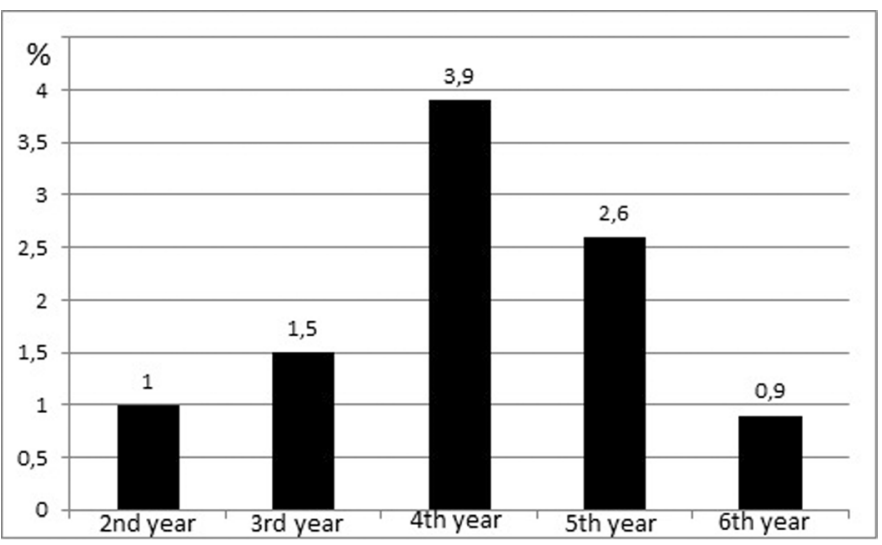

Figure 3 | HPV vaccination rates among female medical students.

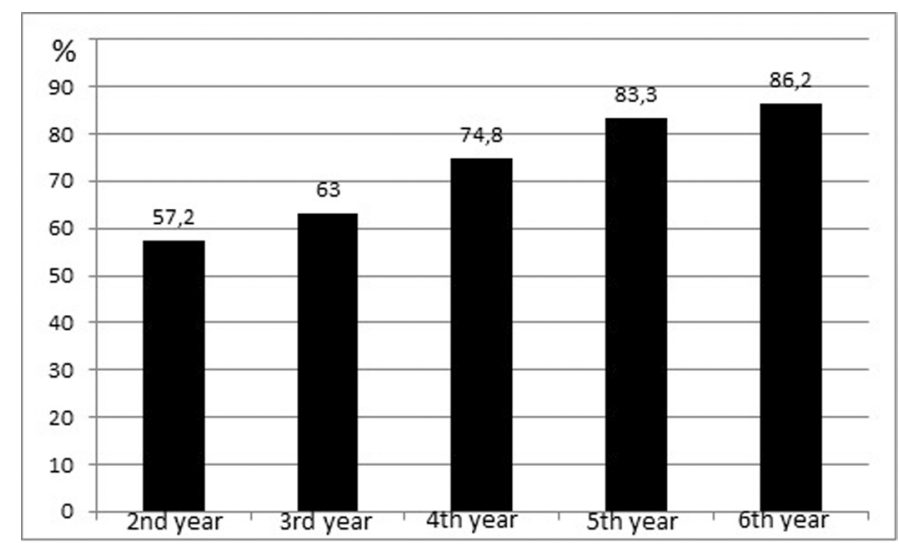

Figure 4 | Number of students that were sexually active. 
purchase the vaccine at one's own expense or check the availability of regional vaccination programs. However, $64.4 \%$ of 2 nd-year students and almost half of 3 rd-year students did not know about HPV vaccine availability. Better knowledge of vaccination exhibited by the 4th- to 6th-year students is probably related to the start of gynecology as a subject in the 4th year of the program. However, almost one-fourth of the 6th-year students still did not know about HPV vaccination. Knowledge of vaccine availability was even lower in medical students from China (11), but it was much higher in students from countries with national HPV vaccination programs $(12,13)$. Studies from Italy have shown that the HPV vaccination rate was much higher in medical students in comparison with the general student population $(13,14)$. It may be assumed that the situation regarding HPV vaccination and knowledge among non-medical Ukrainian students is also worse.

A significantly higher number of our students reported knowl- edge of HPV-related cervical cancer than knowledge of HPV vaccination. Students in the 2nd and zrd years of the program showed a lower rate of HPV-related cervical cancer awareness than their colleagues from the 4th to 6th years. This is probably also related to the start of gynecology as a subject in the 4 th year of the program. Our results showed that in the 2nd year of the program the number of students that did not know about the HPV vaccine was higher than the number of students that were sexually active. Thus, a substantial number of sexually active students did not even know about the possibility of vaccination against HPV.

A significant proportion of female medical students (30.3\%) included in this study were not yet sexually active and would thus be ideal candidates for HPV vaccination because it has been shown that the HPV vaccine is most effective when given before the start of sexual activity. Although 12 to $21 \%$ of our respondents consistently used condoms, they should be aware of the fact that Table 1 | Age at sexual debut.

\begin{tabular}{|c|c|c|c|c|c|}
\hline Age (years) & $\begin{array}{l}\text { Second year of program } \\
(n=119)\end{array}$ & $\begin{array}{l}\text { Third year of program } \\
(n=85)\end{array}$ & $\begin{array}{l}\text { Fourth year of program } \\
\qquad(n=77)\end{array}$ & $\begin{array}{l}\text { Fifth year of program } \\
\qquad(n=65)\end{array}$ & $\begin{array}{l}\text { Sixth year of program } \\
(n=100)\end{array}$ \\
\hline 3 & - & $1(1.2 \%)$ & - & - & - \\
\hline 8 & $1(0.8 \%)$ & - & - & - & - \\
\hline 11 & $1(0.8 \%)$ & - & - & - & - \\
\hline 12 & $2(1.7 \%)$ & - & - & - & - \\
\hline 13 & - & - & - & $1(1.5 \%)$ & $1(1.0 \%)$ \\
\hline 14 & $7(5.8 \%)$ & $1(1.2 \%)$ & $1(1.3 \%)$ & $2(3.1 \%)$ & - \\
\hline 15 & $8(6.7 \%)$ & $4(4.7 \%)$ & $3(3.9 \%)$ & $1(1.5 \%)$ & $4(4.0 \%)$ \\
\hline 16 & $18(15.1 \%)$ & $10(11.8 \%)$ & $8(10.4 \%)$ & $4(6.2 \%)$ & $9(9.0 \%)$ \\
\hline 17 & $28(23.5 \%)$ & $14(16.5 \%)$ & $16(20.8 \%)$ & $11(16.9 \%)$ & $17(17.0 \%)$ \\
\hline 18 & $44(37.0 \%)$ & $33(38.8 \%)$ & $26(33.8 \%)$ & $21(32.3 \%)$ & $26(26.0 \%)$ \\
\hline 19 & $4(3.4 \%)$ & $13(15.3 \%)$ & $13(16.9 \%)$ & $9(13.8 \%)$ & $14(14.0 \%)$ \\
\hline 20 & $2(1.7 \%)$ & $4(4.7 \%)$ & $7(9.1 \%)$ & $10(15.4 \%)$ & $11(11.0 \%)$ \\
\hline 21 & $1(0.8 \%)$ & $2(2.4 \%)$ & $2(2.6 \%)$ & $4(6.2 \%)$ & $10(10.0 \%)$ \\
\hline 22 & $2(1.7 \%)$ & $1(1.2 \%)$ & $1(1.3 \%)$ & $2(3.1 \%)$ & $5(5.0 \%)$ \\
\hline 23 & - & - & - & - & $3(3.0 \%)$ \\
\hline \multicolumn{6}{|l|}{ Invalid answers } \\
\hline 0 & - & $1(1.2 \%)$ & - & - & - \\
\hline 98 & $1(0.8 \%)$ & - & - & - & - \\
\hline "Tactless question" & - & $1(1.2 \%)$ & - & - & - \\
\hline
\end{tabular}

Table 2 | Total number of sexual partners.

\begin{tabular}{|c|c|c|c|c|c|}
\hline $\begin{array}{l}\text { Number of sexual } \\
\text { partners }\end{array}$ & $\begin{array}{l}\text { Second year of program } \\
(n=119)\end{array}$ & $\begin{array}{l}\text { Third year of program } \\
(n=85)\end{array}$ & $\begin{array}{l}\text { Fourth year of program } \\
\qquad(n=77)\end{array}$ & $\begin{array}{l}\text { Fifth year of program } \\
\qquad(n=65)\end{array}$ & $\begin{array}{l}\text { Sixth year of program } \\
\qquad(n=100)\end{array}$ \\
\hline 1 & $54(45.4 \%)$ & $38(44.7 \%)$ & $43(55.8 \%)$ & $28(43.1 \%)$ & $44(44.0 \%)$ \\
\hline 2 & $26(21.8 \%)$ & $23(27.1 \%)$ & $17(22.1 \%)$ & $12(18.5 \%)$ & $15(15.0 \%)$ \\
\hline 3 & $10(8.4 \%)$ & $4(4.7 \%)$ & $7(9.1 \%)$ & $10(15.4 \%)$ & $17(17.0 \%)$ \\
\hline 4 & $6(5.0 \%)$ & $7(8.2 \%)$ & $3(3.9 \%)$ & $4(6.2 \%)$ & $4(4.0 \%)$ \\
\hline 5 & $6(5.0 \%)$ & $4(4.7 \%)$ & $2(2.6 \%)$ & $7(10.8 \%)$ & $7(7.0 \%)$ \\
\hline 6 & $4(3.4 \%)$ & - & $1(1.3 \%)$ & - & $3(3.0 \%)$ \\
\hline 7 & $1(0.8 \%)$ & $2(2.4 \%)$ & $2(2.6 \%)$ & - & $1(1.0 \%)$ \\
\hline 8 & - & $1(1.2 \%)$ & - & $1(1.5 \%)$ & $1(1.0 \%)$ \\
\hline 9 & $1(0.8 \%)$ & - & - & - & $2(2.0 \%)$ \\
\hline 10 & $2(1.7 \%)$ & $1(1.2 \%)$ & $2(2.6 \%)$ & - & $2(2.0 \%)$ \\
\hline 11 & $1(0.8 \%)$ & - & - & - & - \\
\hline 12 & - & - & - & $1(1.5 \%)$ & - \\
\hline 15 & $2(1.7 \%)$ & - & - & $1(1.5 \%)$ & $1(1.0 \%)$ \\
\hline 17 & - & $1(1.2 \%)$ & - & - & - \\
\hline 18 & $1(0.8 \%)$ & - & - & - & $1(1.0 \%)$ \\
\hline 21 & $1(0.8 \%)$ & - & - & - & - \\
\hline 25 & $1(0.8 \%)$ & $1(1.2 \%)$ & - & - & - \\
\hline 30 & - & - & - & - & $1(1.0 \%)$ \\
\hline 35 & - & - & - & $1(1.5 \%)$ & - \\
\hline 56 & $1(0.8 \%)$ & - & - & - & - \\
\hline 67 & - & $1(1.2 \%)$ & - & - & - \\
\hline 111 & $1(0.8 \%)$ & - & - & - & - \\
\hline 300 & - & - & - & - & $1(1.0 \%)$ \\
\hline \multicolumn{6}{|l|}{ Invalid answers } \\
\hline 0 & - & $1(1.2 \%)$ & - & - & - \\
\hline "No" & $1(0.8 \%)$ & - & - & - & - \\
\hline "Tactless question" & - & $1(1.2 \%)$ & - & - & - \\
\hline
\end{tabular}


Table 3 | Total number of sexual partners with at least one act of unprotected vaginal intercourse.

\begin{tabular}{|c|c|c|c|c|c|}
\hline $\begin{array}{l}\text { Number of sexual } \\
\text { partners }\end{array}$ & $\begin{array}{l}\text { Second year of program } \\
(n=119)\end{array}$ & $\begin{array}{l}\text { Third year of program } \\
\qquad(n=85)\end{array}$ & $\begin{array}{l}\text { Fourth year of program } \\
\qquad(n=77)\end{array}$ & $\begin{array}{l}\text { Fifth year of program } \\
\qquad(n=65)\end{array}$ & $\begin{array}{c}\text { Sixth year of program } \\
(n=100)\end{array}$ \\
\hline 0 & $18(15.1 \%)$ & $12(14.1 \%)$ & $17(22.1 \%)$ & 10 (15.4\%) & $12(12.0 \%)$ \\
\hline 1 & $56(47.1 \%)$ & $46(54.1 \%)$ & 37 (48.1\%) & $26(40.0 \%))$ & 44 (44.0\%) \\
\hline 2 & 25 (21.0\%) & 12 (14.1\%) & 13 (16.9\%) & $16(24.6 \%)$ & $18(18.0 \%)$ \\
\hline 3 & $7(5.9 \%)$ & $6(7.1 \%)$ & $3(3.9 \%)$ & $5(7.7 \%)$ & 15 (15.0\%) \\
\hline 4 & $2(1.7 \%)$ & $3(3.5 \%)$ & $3(3.9 \%)$ & $4(6.2 \%)$ & $3(3.0 \%)$ \\
\hline 5 & $2(1.7 \%)$ & $1(1.2 \%)$ & $2(2.6 \%)$ & 1 (1.5\%) & $3(3.0 \%)$ \\
\hline 6 & $3(2.5 \%)$ & - & $2(2.6 \%)$ & - & $1(1.0 \%)$ \\
\hline 7 & $1(0.8 \%)$ & - & - & - & - \\
\hline 8 & $1(0.8 \%)$ & 1 (1.2\%) & - & $1(1.5 \%)$ & 1 (1.0\%) \\
\hline 9 & $2(1.7 \%)$ & - & - & - & $1(1.0 \%)$ \\
\hline 10 & - & - & - & $1(1.5 \%)$ & \\
\hline 13 & - & $1(1.2 \%)$ & - & - & \\
\hline 20 & - & - & - & $1(1.5 \%)$ & \\
\hline 24 & - & $1(1.2 \%)$ & - & - & \\
\hline 25 & - & - & - & - & $1(1.0 \%)$ \\
\hline 50 & - & - & - & - & $1(1.0 \%)$ \\
\hline 56 & $1(0.8 \%)$ & $1(1.2 \%)$ & - & - & - \\
\hline 101 & $1(0.8 \%)$ & - & - & - & - \\
\hline \multicolumn{6}{|l|}{ Invalid answer } \\
\hline "Tactless question" & - & $1(1.2 \%)$ & - & - & - \\
\hline
\end{tabular}

condoms do not provide absolute protection against HPV infection, suggesting that additional protection with the HPV vaccine is crucial. As mentioned above, high cost is the main barrier to $\mathrm{HPV}$ vaccination. In this context, it is encouraging that there is increasing evidence that even a single-dose vaccination may be sufficient to provide prolonged protection against HPV infection and associated diseases $(15,16)$. It may also help to double the number of local vaccination program participants. It is important to note that high price is not the only reason for not being vaccinated (17-20). Only 53.7\% of Italian students in health professions (13) and $48.7 \%$ of Spanish dental students (21) have been vaccinated against HPV. The results of a study from the US on intent to receive the HPV vaccine and reasons for not vaccinating among unvaccinated adolescent and young women highlighted the need to better communicate information regarding the lifetime risk for HPV and the importance of receiving the HPV vaccine prior to sexual initiation (19). A study from Italy (20) showed that factors associated with refusing the HPV vaccination were a lower education level, lower participation in the school seminar on HPV, and lower perception of the HPV vaccine's benefits. The authors of that study concluded that a public health educational program focusing on the HPV vaccine and HPV disease severity, carried out at school or during medical visits, can be useful for improving HPV vaccination uptake. We also conclude that there is an emerging need for vaccination for students starting from their first semester of academic programs. Between 74 to $87.1 \%$ of our students reported unprotected sex with two or fewer partners. They may consider themselves not to be at risk and therefore not needing the HPV vaccination. However, even a single HPV infected partner may be enough to get HPV. Our data on the age of sexual debut showed the importance of a broader information campaign focusing on schoolchildren and their parents. Annual "refresher" courses with education and promotion for all healthcare workers on the frontline of HPV vaccination, as in Slovenia and some other countries, may be also important (22).

\section{Conclusions}

Female medical students showed low knowledge of HPV vaccination and an extremely low HPV vaccination rate, but a higher level of HPV-related cervical cancer awareness. A substantial number of students were not yet sexually active or had never had sex without a condom. HPV vaccination is still beneficial for our respondents. There is an emerging need for students starting from their first semester of academic programs and for a broader information campaign focusing on schoolchildren and their parents.

\section{References}

1. Bruni L, Albero G, Serrano B, Mena M, Gómez D, Muñoz J, et al. ICO/IARC Information Centre on HPV and Cancer (HPV Information Centre). Human papillomavirus and related diseases in Ukraine. Summary Report 10 December 2018. [cited 2019 Apr 27].

2. U 2017 rotsi u yunykh kyyanok vpershe z"yavylasya mozhlyvist' bezkoshtovnoyi vaktsynatsiyi dlya profilaktyky raku shyyky matky - Valentyna Hinzburh. Ukrainian [cited 2019 May 06]. Available from: https://kyivcity.gov.ua/news/u_2017_ rotsi_u_yunikh_kiyanok_vpershe_zyavilasya_mozhlivist_bezkoshtovno_vaktsinatsi_dlya_profilaktiki_raku_shiyki_matki_valentina_ginzburg/

3. L'vivshchyna vpershe zakupyla vaktsynu vid papilomavirusu, shcho sprychynyaye rak shyyky matky. Ukrainian [cited 2019 May 06]. Available from: https:// zik.ua/news/2017/06/08/lvivshchyna_vpershe_zakupyla_vaktsynu_vid_ papilomavirusu_shcho_sprychynyaie_rak_shyyaky_1110991

4. Na Prykarpatti rozpochaly vaktsynatsiyu vid raku shyyky matky. Ukrainian [cited 2019 May 06]. Available from: https://www.radiosvoboda.org/a/news/ 28065856.html
5. Owsianka B, Gańczak M. Evaluation of human papilloma virus (HPV) vaccination strategies and vaccination coverage in adolescent girls worldwide. Przegl Epidemiol. 2015;69:53-8, 151-5.

6. Humenna I, Chernyshov PV. Pilot study on HPV-related cancer awareness and HPV vaccination in Ukrainian students. Int J Dermatol. 2017;56:e129-30.

7. Nweke MC, Okolo CA, Daous Y, Esan OA. Challenges of human papillomavirus infection and associated diseases in low-resource countries. Arch Pathol Lab Med. 2018;142:696-9.

8. Seme K, Maver PJ, Korać T, Canton A, Částková J, Dimitrov G, et al. Current status of human papillomavirus vaccination implementation in central and eastern Europe. Acta Dermatovenerol Alp Pannonica Adriat. 2013;22:21-5.

9. Dillner J, Nygård M, Munk C, Hortlund M, Hansen BT, Lagheden C, et al. Decline of HPV infections in Scandinavian cervical screening populations after introduction of HPV vaccination programs. Vaccine. 2018;36:3820-9. 
10. Mesher D, Panwar K, Thomas SL, Edmundson C, Choi YH, Beddows S, et al. The impact of the national HPV vaccination program in England using the bivalent HPV vaccine: surveillance of type-specific HPV in young females, 2010-2016. J Infect Dis. 2018;18:911-21.

11. Wen Y, Pan XF, Zhao ZM, Chen F, Fu CJ, Li SQ, et al. Knowledge of human papillomavirus (HPV) infection, cervical cancer, and HPV vaccine and its correlates among medical students in southwest China: a multi-center cross-sectional survey. Asian Pac J Cancer Prev. 2014;15:5773-9.

12. Staples JN, Wong MS, Rimel BJ. An educational intervention to improve human papilloma virus (HPV) and cervical cancer knowledge among African American college students. Gynecol Oncol. 2018;149:101-5.

13. Santangelo OE, Provenzano S, Firenze A. Knowledge of sexually transmitted infections and sex-at-risk among Italian students of health professions. Data from a one-month survey. Ann Ist Super Sanita. 2018;54:40-8.

14. Cocchio S, Bertoncello C, Baldovin T, Buja A, Majori S, Baldo V. Self-reported genital warts among sexually-active university students: a cross-sectional study. BMC Infect Dis. 2018;18:41.

15. Gilca V, Salmerón-Castro J, Sauvageau C, Ogilvie G, Landry M, Naus M, et al. Early use of the HPV 2-dose vaccination schedule: leveraging evidence to support policy for accelerated impact. Vaccine. 2018;6:4800-5.

16. Markowitz LE, Drolet M, Perez N, Jit M, Brisson M. Human papillomavirus vaccine effectiveness by number of doses: systematic review of data from national immunization programs. Vaccine. 2018;36:4806-15.
17. Patel PR, Berenson AB. Sources of HPV vaccine hesitancy in parents. Hum Vaccin Immunother. 2013;9:2649-53.

18. Thompson EL, Vamos CA, Sappenfield WM, Straub DM, Daley EM. Relationship status impacts primary reasons for interest in the HPV vaccine among young adult women. Vaccine. 2016;34:3119-24.

19. Liddon NC, Hood JE, Leichliter JS. Intent to receive HPV vaccine and reasons for not vaccinating among unvaccinated adolescent and young women: findings from the 2006-2008 National Survey of Family Growth. Vaccine. 2012;30:267682.

20. Restivo V, Costantino C, Fazio TF. Factors associated with HPV vaccine refusal among young adult women after ten years of vaccine implementation. Int J Environ Res Public Health. 2018;15. pii: E770. doi: 10.3390/ijerph15040770.

21. Lorenzo-Pouso Al, Gándara-Vila P, Banga C, Gallas M, Pérez-Sayáns M, García A, et al. Human papillomavirus-related oral cancer: knowledge and awareness among Spanish dental students. J Cancer Educ. 2018 May 10. doi: 10.1007/ S13187-018-1373-1. [Epub ahead of print].

22. Šterbenc A, Maver PJ, Poljak M. Recent advances in prophylactic human papillomavirus (HPV) vaccination: a review of key literature published between September 2017 and September 2018. Acta Dermatovenerol Alp Pannonica Adriat. 2018;27:193-201. 